\title{
Boosting innovative business ideas through hackathons. The "Hack for Travel" case study
}

\author{
Stefano Franco \\ LUISS University, Roma, Italy \\ Angelo Presenza \\ University of Molise, Campobasso, Italy, and \\ Antonio Messeni Petruzzelli \\ Polytechnic University of Bari, Bari, Italy
}

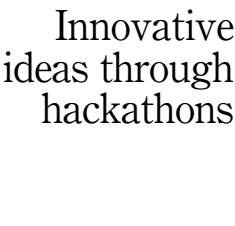

413

Received 23 June 2021

Revised 4 August 2021 Accepted 7 September 2021

\begin{abstract}
Purpose - Technological platforms encourage the exchange of knowledge and creation of new ideas that create new value for participating members who pool and combine their knowledge, facilities, tools and skills, thus contributing to the development of innovative solutions. This paper focuses on hackathon platforms, working as open innovation intermediaries, investigating their role and functions and exploring how they encourage the collaboration and the innovativeness among participants in order to boost their innovative new ideas.

Design/methodology/approach - The research method is a qualitative design that includes in-depth interviews of ten stakeholders that play different roles in "Hack for Travel," the case under analysis. It is a hackathon organized entirely online, as a response to the crisis generated by coronavirus disease 2019 (COVID-19).

Findings - Findings revealed six processes developed by the hackathon platform used to effectively organize the event and facilitate participants to cooperate and share knowledge in order to boost the spread of innovative ideas. Results identify how hackathons should be organized and through which processes they work as innovation platforms.

Originality/value - This is one of the first attempts to study the increasing phenomenon of hackathons, providing theoretical contribution and practical implications about their role in developing innovation.

Keywords Open innovation, Open innovation intermediaries, Digital platform, Innovation contest, Hackathon Paper type Research paper
\end{abstract}

\section{Introduction}

Innovation has been defined as the generation, acceptance and implementation of new ideas, processes, products or services (Baregheh et al., 2009). It has been widely recognized as a strategic issue to achieve growth and long-term oriented success in rapidly changing markets (Day and Schoemaker, 2016), because it allows companies to quickly respond to the constant request for new experiences and customer empowerment (Roper and Tapinos, 2016), the sustainability challenges (D'Angelo and Magnusson, 2020; Denicolai et al., 2021), the regulatory forces (Huang et al., 2016) and to respond to uncertain conditions (Blind et al., 2017). Innovation process no longer needs to be effectively managed alone, as external

C Stefano Franco, Angelo Presenza and Antonio Messeni Petruzzelli. Published by Emerald Publishing Limited. This article is published under the Creative Commons Attribution (CC BY 4.0) licence. Anyone may reproduce, distribute, translate and create derivative works of this article (for both commercial and non-commercial purposes), subject to full attribution to the original publication and authors. The full terms of this licence may be seen at http://creativecommons.org/licences/by/4.0/legalcode

"The authors would like to thank Dr. Cristiana Masciotta for her precious support provided during the data collection".

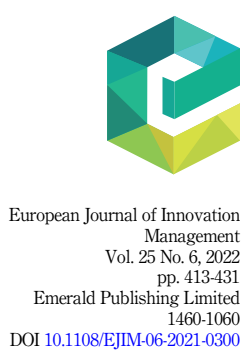


EJIM

25,6

partnerships can be beneficial (Dahlander and Gann, 2010; Love et al., 2014). It means that "valuable ideas can come from inside places, external ideas and external paths to the market on the same level of importance as that reserved for internal ideas and paths" (Chesbrough, 2003, p. 43).

In line with the increasing attention to innovation in tourism and hospitality, research on collaboration for innovation in this industry has quickly expanded in the past years (Baggio and Del Chiappa, 2014; Gomezelj, 2016). ICT is probably the strongest driving force for changes in tourism (Buhalis, 2019), so that digital technologies are able to completely reengineer the process of developing, managing and marketing the entire tourism industry (Cuomo et al., 2021; Rezaei et al., 2016). Several scholars (e.g. Baglieri and Consoli, 2009; Egger et al., 2016; Gomezelj, 2016; Marasco et al., 2018) have also emphasized the preeminent information and communication technology's (ICT's) role in facilitating "collective innovation" in tourism. The large diffusion of digital technologies has radically changed firms' open innovation (OI) strategies by creating the processes of users' empowerment, as well as larger and more highly participated innovation processes (Ferraris et al., 2017; Mount and Martinez, 2014; Natalicchio et al., 2018). This is because as low cost and ubiquitous tools, digital technologies allow firms to tap into the knowledge and experiences of a larger number of actors, allowing them to actively participate in the OI process (Brunswicker and Vanhaverbeke, 2015).

In the interorganizational perspective adopted in this article, OI translates into a multitude of organizations that "participate in innovation ecosystems that integrate a diverse set of innovation actors throughout the various stages of the innovation process" (Bogers et al., 2017, p. 16).

A key principle underlying this phenomenon is the proliferation of intermediaries that intervene for facilitating peer-to-peer sharing of ideas, information, goods and services, and thereby creating value for all participants (Spender et al., 2017). As stated by Troise et al. (2021, p. 2), "open innovation intermediaries (OIIs) play a key role in the OI process ensuring access to a multitude of users". They are able to regulate activities and, in so doing, to generate network effects and create value by facilitating relationships (Kokshagina et al., 2017). Such players leverage a broad community of people in the creation and development of innovative ideas, obtaining and sharing new knowledge (Aleksić et al., 2021; Howells, 2006). They serve as virtual knowledge brokers (Verona et al., 2006) and facilitators (Sieg et al., 2010) to assist knowledge flows that support stakeholders to co-ideate and co-design business ideas (Urbinati et al., 2020). To solve this role, they usually use online, web-based platforms able to stimulate, facilitate and support the ongoing interactions and collaborations among different stakeholders and to increase the combination of the complementary capabilities necessary to develop innovative products and projects oriented to value co-creation activities (Presenza et al., 2014; Troise et al., 2021).

Among these types of platforms, online ideas contests (Cappa et al., 2019; Ghezzi et al., 2017; Morgan and Wang, 2010; Terwiesch and Xu, 2008) are increasingly used to leverage the creativity, skills and intelligence of thousands of individuals on the Internet. They enable interaction with other like-minded peers, building relationships and establishing a sense of community (Terwiesch and Xu, 2008). Users can collaborate, discuss, share insights and learn from the aggregate knowledge and feedback of others, while competing for prizes (Hutter et al., 2011). In this perspective, the knowledge diversity of the different actors involved appears to be an additional benefit of online interactions. Also known as hackathons, these contests are becoming an important research area due to the opportunity they have to facilitate a variety of initiatives, such as implementing OI practices to discover new ideas (Karlsen and Løvlie, 2017), increasing the growth of entrepreneurship (Kitsios and Kamariotou, 2018) and solve environmental, social or business challenges (Granados and Pareja-Eastaway, 2019). However, the functioning of hackathons and how they allow 
innovators to develop business ideas is still an overlooked topic in the literature. This research gap increasingly calls for investigation, because hackathons are by now recognized as source of innovation for companies (Lifshitz-Assaf et al., 2020), and the understanding of their functioning is needed to design them in the most effective possible way, guaranteeing the outcome of successful and marketable business ideas. The aim of this research is to investigate the role and functions of hackathon platforms and explore how they encourage the collaboration and the innovativeness among participants. Hereby, we support the understanding for how hackathon platforms, working as OIIs, can take further steps in supporting hackathon participants in boosting their innovative and sustainable tourism new ideas. Our research questions are formulated accordingly:

(1) Which are the processes that hackathon platforms use to effectively organize the event to support innovative tourism projects?

(2) How do hackathon platforms facilitate OI and knowledge flows supporting the interaction among participants to co-ideate and co-design innovative solutions?

Assumed the novelty of the phenomenon under investigation and the inductive nature of the research questions, the study adopts a qualitative, case-based approach that may enable the exploration of a phenomenon within its context, by using a wide range of data sources (Yin, 1994). The selected case is "Hack for Travel." The choice of this case study is based on the combination of theoretical interests and ongoing research activities (Siggelkow, 2007). Indeed, "Hack for Travel" represents a novel and successful example of hackathon initiatives. It is one of the first attempts within the Italian context combining the possibilities offered by the power of Open Data, and it has been one of the most rapid and concrete reactions to the crisis generated by the COVID-19 in the tourism industry. By providing practical solutions to the pandemic, "Hack for Travel" represents a sustainability initiative aimed at designing strategies to relaunch tourism in the pandemic era that has deeply changed tourist behaviors, asking for solutions to overcome uncertainty and anxiety (Sigala, 2020). Main results refer to the processes utilized by OII to organize and run the hackathon. In particular, the study identified six processes, the first three as answer to the first RQ and the last three as answer to the second RQ. In this way, we contribute to the debate going on about OI by unfolding the processes that make hackathons valuable tools to generate innovative ideas in a collaborative process of idea generation. The remaining of the paper unfolds as follows. The second section develops the theoretical background based on two subsections. First of all, an overview on the meaning of hackathon platforms is presented in order to get insights on this emergent phenomenon. Second, functioning and role in support interactions and collaborations among hackathon participants are presented and discussed using the specific theoretical lenses of OIIs. The third section presents the methodology used in order to conduct the qualitative analysis using the case study "Hack for Travel." Findings present processes unveiled by the empirical analysis. The paper concludes with a final section that discusses the findings and proposes theoretical and managerial implications as well as limitations and future research directions.

\section{Theoretical background}

\subsection{The rise of hackathon platforms}

Hackathons have been described as problem-focused computer programming events as well as contests to brainstorm, develop, test and launch ready to use prototypes that can then be transformed into full-scale services or products (Sigala and Ukpabi, 2019).

Hackathons operate as contests during which participants get together in an intense, short-duration meeting, usually between 24 and $48 \mathrm{~h}$. While some organizers choose to identify a specific problem for participants to find a solution for, other hackathons have

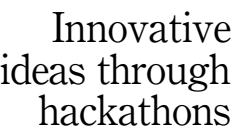
(1) 
EJIM

25,6

themes with several focus areas. In any case, the time, size and shape of a hackathon differ depending on the competencies available to the organizers and the considerable resources to prepare, run and follow-up that they are called to invest on the event (Medina Angarita and Nolte, 2020). During the competition, teams make great use of software solutions and open data that are freely accessible online by anyone interested (Cappa et al., 2021; George et al., 2014). Such data can be reutilized without barriers due to technical restrictions, and reused without constraints, being these provided in open access (Kitsios and Kamariotou, 2018). Teams work to develop a new solution to a challenge (Komssi et al., 2015) and so to create new service ideas and prototypes (Chowdhury, 2012). These ideas and prototypes are then evaluated by an expert jury, and prizes are awarded to the team adjudged to have performed better (Briscoe and Mulligan, 2014).

Hackathons are useful citizen engagement tools in inspiring entrepreneurial interest in line with the principles of the collaborative and sustainable economy (Bresciani et al., 2018; Sigala and Ukpabi, 2019), in which several stakeholders are involved towards the achievement of shared benefits. They attract stakeholders from different backgrounds and professional fields and use design-thinking approaches (Stickdorn et al., 2011) to support connections and stimulate knowledge exchange. They offer a wide range of services to enhance active participation, to develop ideas/products/solutions to problems in interdisciplinary fields and, finally, to answer firm's needs or market opportunities (Verona et al., 2006).

Born as physical events, hackathons are moving more and more virtually by inviting and engaging masses of participants simultaneously from across different geographies and time zones, pushed by the rise of the platform economy that drives the improvement of the online presence, the enhancement of interactions and the development of networking structures as well as digital collaborations (Acciarini et al., 2021; Bolici et al., 2020).

\subsection{Hackathon platforms and knowledge co-creation}

Hackathon platforms can serve several purposes as for example being designed to promote innovation and sustainability in the tourism industry. In particular, working as OIIs, they can help destinations and tourism organizations to develop sustainable initiatives, while achieving competitive advantage (Del Vecchio et al., 2018) due to their ability to give life to an environment within which fruitful discussions can take place and stakeholders can engage, ultimately creating new collaborations (Lalicic, 2018; Urbinati et al., 2020).

Hackathon platforms connect a variety of users that can easily get together and exchange value (Evans and Schmalensee, 2016). Hence, it emerges how the creation of value through platforms is dependent on the possibility to enable interactions among different sides of the competitive arena (McIntyre and Srinivasan, 2017). They can support stakeholders with several functions, as suggested by Howells (2006): helping to provide information about potential collaborators; brokering a transaction between two or more parties; acting as a mediator, or go-between, bodies or organizations that are already collaborating; and helping find advice, funding and support for the innovation outcomes of such collaborations. According to Kuang et al. (2019), platforms encourage the exchange of knowledge and creation of new ideas based upon existing and new resources that, consequently, create new value for participating members who pool and combine their knowledge, facilities, tools and skills (Lalicic, 2018). In doing so, platforms can facilitate effective collaboration among stakeholders leading to fruitful innovative projects (Haugland et al., 2011). Such interactions favor the positive impact that OI has on the development and diffusion of sustainabilityoriented innovations through the implementation of a number of organizational processes (Kennedy et al., 2017).

A key principle underlying the effective interactions among different actors is the ability of an intermediary to facilitate peer-to-peer sharing of ideas, information, goods and services, 
and thereby creating value for all participants. As stated by Troise et al. (2021, p. 2), "OIIs play a key role in the OI process ensuring access to a multitude of users". OIIs are able to regulate activities and, in so doing, to generate network effects and create value by facilitating relationships, thus obtaining and sharing new knowledge (Howells, 2006). Within the useful web-based platforms characterized by numerous web tools, OIIs stimulate, facilitate and support ongoing interactions and collaborations oriented to value co-creation activities (Troise et al., 2021). They facilitate meeting, collaboration and exchange of innovation seekers, with specific needs, with solvers offering solutions, hence becoming among the most relevant locus for the generation of new ideas (Briscoe and Mulligan, 2014).

OIIs are able to stimulate the interactions among different stakeholders and to increase the combination of the complementary capabilities necessary to develop innovative products and projects (Boudreau and Lakhani, 2009; Colombo et al., 2014). However, as Antikainen et al. (2010) stated, managing an online innovation community is quite challenging. Supporting and facilitating such interactions are difficult given the lack of offline communication traits and interactions with others (Antikainen et al., 2010). To reduce these challenges, as well as to boost participants' sense of collaboration, defining interesting objectives is crucial (Adamczyk et al., 2012). Furthermore, Adamczyk et al. (2012) argue that the intermediary needs to be aware of participants' motivations. It has to facilitate an exciting experience to all members and, thus, pay attention to the atmosphere and communication styles (Lee et al., 2010), in other terms to work for spreading among all the participants a sense of belonging to a community (Antikainen et al., 2010).

This study looks for new insights on the functioning of a hackathon platform and so on how it works for supporting hackathon participants in boosting their innovative and sustainable tourism new ideas. In order to support this goal, the analysis of the case study "Hack for Travel" is presented in the next sections.

\section{Methodology}

A single exploratory case study (Yin, 1994) has been conducted. The study of hackathon OIIs within the context of tourism represents a contemporary phenomenon (Sigala and Ukpabi, 2019). In fact, looking at the tourism and hospitality industry, researches specifically focused on the role of hackathon platforms are rare. In spite of that, the proliferation of "opening-upmovements" in the tourism and hospitality industry-recently labeled by Egger et al. (2016) as open tourism-highlights the increasing interest on OI developments in this sector (Grissemann et al., 2013). This research topic poses "how" and "why" questions, and the case study approach is useful for addressing these issues, since it allows to study the phenomenon more in depth than a large-scale survey or an experimental research (Gummesson, 2017). A case study is considered a suitable research approach when exploring emerging complex phenomena (e.g. hackathon development and use) within reallife settings (Eisenhardt, 1989), in order to induce theories (Benbasat et al., 1987). Additionally, the case study approach is greatly suggested for researches where theories are at their formative stage (Benbasat et al., 1987).

\subsection{Case selection}

The selected case is "Hack for Travel," an online hackathon run between April 30 and May 2, 2020 in Italy. The choice of analyzing the tourism industry in Italy is relevant since in 2019 the industry was worth about $13 \%$ of gross domestic product (GPD) in the country. After the pandemic, tourism business and economy have decreased dramatically, calling for a rapid recover. In this sense, "Hack for Travel" has been one of the first initiatives that tried to put together several diverse actors to discuss the future of tourism after COVID-19. The event had 
EJIM

25,6

418

a great resonance as confirmed by Data Appeal-the company that launched and managed this hackathon. The website of the event is hackfortravel.org, while a Facebook page has been used to perform live meetings in order to stay in touch with all the participants. All the information has been also bounced on all social networks with the hashtag \#hackfortravel. Since the whole event was run online, teams worked using several online platforms to communicate and collaborate during the event. There were more than 1,200 registered participants, over 300 applications as mentors, 150 of whom have followed and advised the working groups. 90 projects applied and 69 arrived to the final submission. Over $10 \mathrm{~h}$ of FB live streaming with tens of thousands of views and comments.

The purpose of this event was "to organize a marathon of ideas completely online to put many brilliant minds to work on operational, practical solutions, useful to get out of this situation and face the next months of living with the virus with greater hope" (CEO of Data Appeal). The goal of the project was to "provide an online platform capable of creating a sense of community in which to share experiences, skills and emotions" (CEO of Data Appeal).

\subsection{Data collection}

Two different techniques of data collection have been used, as semi-structured interviews and secondary data analysis.

3.2.1 Secondary data. We started by collecting various information retrieved from various sources. We have constantly monitored the official website and the social media, in particular, the official Facebook page. In addition, we read eight interviews in newspapers and magazines. Information from those sources allowed enriching the precise description of "Hack for Travel."

3.2.2 Semi-structured interviews. We collected primary data via face-to-face interviews in January 2021. The authors jointly interviewed 10 of the main informants of "Hack For Travel" with the goal of providing a managerial perspective (Eisenhardt and Graebner, 2007). Table 1 lists all the interviewees and the main information about them. An identification code was assigned to each one in order to facilitate the management of the findings. The semistructured interviews were presented introducing the general aim of the study without making presumptions on the topic. In this way, we encouraged interviewees to talk freely about the aspects they thought to be more relevant.

Interviews were semi-structured and open-ended and lasted from one hour and ten minutes to one hour and forty minutes. Questions were designed to provide us with a clearer understanding of the dynamics that occur in an online hackathon and were mainly focused around the following: what are the relevant actors involved and what is their role in supporting innovation for the tourism industry? Which are the competences needed to make "Hack for Travel" successful? What are the main differences with a physical hackathon?

The sample of the interviewees of hack for travel

\begin{tabular}{lll}
\hline Code & Short bio & Role in the hackathon \\
\hline i1 & CEO of data appeal & Organizer \\
i2 & Hotel manager & Organizer and mentor \\
i3 & Hotel manager and expert in cultural tourism & Organizer and mentor \\
i4 & Freelance consultant in tourism policy & Mentor \\
i5 & Expert in communication and open innovation & Mentor \\
i6 & Freelance consultant in tourism marketing & Mentor \\
i7 & Former employee data appeal & Mentor \\
i8 & Professor of tourism & Mentor \\
i9 & Freelance consultant in destination management & Mentor \\
i10 & Manager in the energy industry & Innovator \\
\hline
\end{tabular}




\subsection{Data analysis}

The analysis of data followed an inductive and iterative process (Miles and Huberman, 1984; Strauss and Corbin, 1997). Specifically, we investigated the process undertaken in running "Hack for Travel" looking for the main processes used to facilitate the interaction among participants in order to support the creation of innovative and sustainable tourism projects. The first step in the analysis was to transcribe each interview (verbatim) after it had taken place. Given the number of interviews, we opted for a manual coding method: codes emerged as the result of a search for consensus among subjective formulations of each research member. At the end we came out with a set of 180 relevant quotes from the interviews.

Furthermore, notes and memos were written during and after the interviews and were triangulated with the audio to strengthen the validity and credibility of the research (Miles and Huberman, 1984). After this initial step, we independently read through the primary and secondary sources to form a comprehensive understanding of the case. Then, we assembled the data into tables to facilitate comparisons and recognized from the analysis the importance of specific skills and resources needed to manage the high complexity present in an event like this, as well as the main processes of their successful application. Data were manually coded to identify empirical themes. Key words, phrases, sentences and paragraphs from the transcripts, memos, notes and secondary data were underpinned by the emerging analysis (Miles and Huberman, 1984). The analysis process was not linear; rather, it proceeded iteratively, moving between data, emerging patterns and the literature until the data were refined into adequate conceptual themes (Eisenhardt, 1989).

Based on the identified concepts, we came out with a set of codes for each concept. The coding process has been highly iterative and has occurred by contrasting preliminary codes definition with original data. Sometimes a re-coding was necessary (see Table 2 for the final coding scheme). We searched for patterns and relationships among concepts and formulated an analytical framework to address our original research questions. Finally, as described by Eisenhardt (1989), we conducted a further series of iterations between our data, both secondary and primary, and the literature on OIIs, in order to refine the emerging model and better identify the theoretical foundations of our arguments.

\section{Findings}

Thanks to the secondary data and the relative deepening provided by interviews, it was possible to define the stakeholders involved in the hackathon and the different roles they played in the process of innovative idea generation. They are organizers, sponsors, innovators, mentors and the jury that is composed by experts in the field and decides the winning projects.

\begin{tabular}{lll}
\hline Research questions & Concepts & Hackathon functions \\
\hline $\begin{array}{l}\text { 1. Which are the processes that } \\
\text { hackathon platforms use to effectively } \\
\text { organize the event to support innovative } \\
\begin{array}{l}\text { and sustainable tourism projects? } \\
\text { organization of the event }\end{array}\end{array}$ & $\begin{array}{l}\text { Processes performed by the } \\
\text { hackathon platform for the }\end{array}$ & $\begin{array}{l}\text { - Organizing the platform and } \\
\text { the activities } \\
\text { - Attracting the right mix of } \\
\text { competences }\end{array}$ \\
$\begin{array}{ll}\text { 2. How do hackathon platforms facilitate } \\
\text { OI supporting the interaction among } \\
\text { participants to co-ideate and co-design } \\
\text { innovative solutions? }\end{array}$ & $\begin{array}{l}\text { Processes performed to support } \\
\text { interactive OI }\end{array}$ & $\begin{array}{l}\text { the industry } \\
\text { - Setting the best conditions } \\
\text { for knowledge sharing and } \\
\text { idea co-creation }\end{array}$
\end{tabular}

Innovative ideas through hackathons

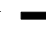


EJIM

25,6

"Hack For Travel" born by an idea of three entrepreneurs operating in the tourism sector. These three subjects were in charge of organizing the hackathon, selecting the participants and managing the events during its development. One aspect of particular interests regards what drives an entrepreneur in investing time and money in a non-profit activity like "Hack For Travel." According to the words of one of the three organizers (i1), the development of the hackathon was driven by ethical motivations, i.e. by the need of giving a rapid response to the pandemic creating a sense of community in the whole industry:

It is not our economic interest to organize a hackathon. It is high demanding. But after the lockdown we wanted to immediately do something positive for the industry and all the actors involved that were in a deep crisis.

With such a positive spirit in mind, the idea was to use this opportunity to explore possible innovations as solution to a disruptive crisis. As the regulation of "Hack for Travel" available on the website states:

The main objective is to understand how to face the situation generated by COVID-19 and start again stronger than before, also thanks to technological and innovative solutions. The online hackathon is aimed at the innovation ecosystem, startups, innovators and all operators in the world of tourism and culture. It is a social goal.

Sponsors are the organizations looking for innovative ideas to solve problems. Such organizations set a monetary prize as a reward for the best innovative project. Their participations have a double function: from one side they can explore innovative ideas at a relatively low cost, and on the other side they work as attractor for innovators and mentors. According to one of the mentors (i2), we interviewed:

They have a return out of their participation in terms of exploration of innovative solutions to their problems. And where else you can find these incredible possibilities by investing only 2,000 or 10,000 euros?

Innovators participate to the hackathon to create a new idea. As one of the winning innovators said in its interview (i10), participating to "Hack for Travel" was a great opportunity for innovators because:

You can express yourself in a path that can be recognized by experts of the field as a valuable outcome for tourism. And this happens rapidly, avoiding the long path of start-ups where you spend 3 or 4 years in search of funds.

In addition, "Hack for Travel" worked as an educational platform for them, where they had the chance to meet experts and leading companies. As i4 said:

I think the added-value of the hackathon was the education it provided to the innovators, in particular for the youngest. It gave them the possibility to understand the relevant issues of the industry and what it means to work in group and doing business.

Mentors are the experts whose role is to check for the innovators' projects and help them to deliver final works. As one of the interviewed mentors (i7) told us:

I participated as a mentor because I have skills that I can make available to the participating teams. Mentors put their experience at the service of younger people who need to be guided.

Typical mentors are entrepreneurs, consultant, professors skilled in highly differentiated topic such as destinations, hospitality, digital technologies and marketing. There were two types of mentors: the first ones were assigned to the teams and constantly check for their advancements. The second ones were not assigned to any specific team but had vertical 
competences at the service of all the teams that have the possibility to ask them for specific needs related to specific topics. One of the organizers (i3) said:

The full-time mentors had a specific project to follow and a specific team. While the part-time mentors were consulted on call, at set times when they were available, on specific topics. For example, there were vertical mentors on digital marketing rather than engineering design.

The following sub-sections will present findings related to the two research questions and discuss the related processes that the hackathon platform "Hack For Travel" concretely utilized to organize the event and facilitate the interaction among the hackathon participants, in an OI perspective.

\subsection{The process performed by the hackathon platform to organize the event}

At the base of the "Hack For Travel" platform, there was the selection of a solid technological infrastructure allowing an effective dialog among all the stakeholders involved. The selection of the right and reliable platform on which basing the event was fundamental because all the interactions should have been taken in there. It represents the first process through which this kind of hackathon allows participants to generate innovative ideas (Table 3). Several online tools have been made available to the participants. In line with the no-profit, ethical principles of the event, much of the premium service of these tools have been made available for free thanks to specific agreements that the organizers stipulated with the company owners of these software. One specific example of that has been the collaboration with Slack, a software that falls into the category of business collaboration tools used to send instant messages to team members. As il said:

The selection and organization of the technology hosting the platform was at the base of the whole hackathon. We used Slack which is a collaboration, chat platform. We asked Slack to give us the premium version for free for a few months, and they gave it to us.

After the platform selection there was the need to select all the participants from many requests. This further process is also fundamental for the effective development of the hackathon (Table 3). The selection of the best innovators and mentors lead to the creation of the most valuable ideas for companies and so it is at the base of the innovation generation process of the event. As one of the mentors (i4) said:

The "pre" is a crazy job. The challenge lies in selecting people who have different profiles and skills, in this case the mentors, with those with whom they will interact with, the innovators.

For this reason, selecting the right competences to involve in the process is the guideline to drive such a choice and the key factor for the effective organization of the hackathon. Once the

\begin{tabular}{llll}
\hline $\begin{array}{l}\text { Research } \\
\text { question }\end{array}$ & $\begin{array}{l}\text { Processes } \\
\text { RQ1 }\end{array}$ & Label & Meaning \\
\hline Process 1 & $\begin{array}{l}\text { Technological } \\
\text { infrastructure setup }\end{array}$ & $\begin{array}{l}\text { Setup of the technological infrastructure to favor the } \\
\text { relationship among the different stakeholders } \\
\text { involved in the process of idea generation } \\
\text { Selection of mentors and innovators that could } \\
\text { co-develop the most valuable innovations thanks to } \\
\text { the right set of advanced and diversified skills } \\
\text { The involvement of the most important public and } \\
\text { private sponsors to identify the most relevant topics } \\
\text { on which providing innovative solutions }\end{array}$
\end{tabular}

Source(s): Authors' elaboration
Innovative ideas through hackathons 
EJIM

25,6

technology aspect is solved, the selection of the partners should be done according to the competences they bring in, and to their network capabilities that helps the spread of knowledge and the generation of innovative ideas. This is particularly true for the selection of the mentors that are the ones who guide innovators towards the development of their solutions. As il said:

Besides technology, there are two skills absolutely needed by mentors. The first one is a domain competence: you need somebody who knows the industry, its challenges, and what can bring value to the sector. The second one is their ability to build a valuable network with all the other parties involved.

Moreover, in order to generate innovation coming from very diversified sources of knowledge, one of the criteria was also selecting experts from very differentiated background as i8 said:

In hackathons, since they are open to everyone, you are also able to connect skills which come from different worlds, which may even be very different from yours. And that creates innovation.

Besides organizing the platform and the related technological aspects needed, the involvement of key actors represents the third process (Table 3), as it was necessary to create the right awareness for the hackathon. The right awareness guarantees the participation of skilled innovators and mentors. The involvement of well-known sponsors, both private companies and public institutions in the tourism industry, was thus needed mainly for two reasons: on one side it brought high-level skills and relevant problems to solve. On the other side it was an attractor of the best competences available. Indeed, it represented a great possibility for all the relevant actors that wanted to bring their contribution to the industry in a high-level event in which some of the most important Italian and international tourism organizations were involved. As reported on the website, "Hack For Travel" was able to involve public actors such as the Ministry of Tourism and the National Agency of Tourism (ENIT), and private actors such as Amadeus, Best Western and Alpitour. So, the network capabilities and the social capital heritage owned by the organizers were also a source of successful development of the event. One of the mentors (i9) said that:

The ability to network, to involve relevant actors, without anyone being paid was a fantastic and determinant skill for the organizers. They involved people who somehow had their own expertise, each one for their own.

This is concisely underlined also by the organizer, i.e. i1:

You must have a strong network before starting, because without it you cannot organize a hackathon.

On the other side of the coin, for the innovators the participation could mean an effective promotional tool to hook relevant partners or investors and start creating their own network. As the innovator (i10) said:

After the hackathon our idea has appeared in various magazines. We were contacted simply by opening a page on social media, there were several curious people. So, reputation is certainly another advantage of participating in a hackathon that has a strong relevance on the web.

\subsection{The interactive OI processes created by hackathon platforms}

The main role of the hackathon platforms is to generate business ideas that represent valuable solutions to the problems raised by companies and institutions. In the case of "Hack For Travel," which has been organized as a fast response to the COVID-19 crisis, such idea generation needed to be quick and disruptive to find new opportunities to a situation that 
was, and still continues to, downsizing the industry, upsetting the consolidated paradigm of tourism. In such a situation, the need of creating an environment that allowed innovators to find solutions in few days, required the systemization of the three processes identified above: the setup of the right technological infrastructure (process 1) capable of hosting skilled innovators (process 2) that should find solutions to weaknesses identified by the most relevant actors in the industry (process 3 ). First, the setup of the right technology to use was just the first step. The participants needed to find a well-structured organization that facilitates the interactions among them while also providing private spaces in which each team could develop its own project. Actors needed to be educated to avoid costs of adaptation that would have been detrimental for such a short and intensive event. This is highlighted by the words of i4:

There were dozens of people who had to use a system that they had never used before, and you have to make people able to interact with these information tools and it is not easy. There were meetings in which we organized and familiarized ourselves with both the method and the technical part.

This process-named technological education (Table 4)-allowed "Hack For Travel" to create interaction among the participants and particularly organizers, sponsors and mentors. In this way, once the event started, everyone knows exactly what to do and how to use the platform, being able to guide innovators in their creative process.

That said, an effective organization and the right know-how from the participants allowed all the innovators to address highly relevant topics to which trying to provide a solution, avoiding issues and time wastes that may not be in line with the aims of the hackathon and, in turn, of the whole industry. According to i7:

After having created the teams, the participants read the briefs and select one of them on which to focus. In doing so, they avoid time waste due to the selection of scarcely relevant issues.

Once the brief was selected everything should work to favor the creation of the ideas and so the right interaction system to favor the dialog between teams and mentors. Supported by the technological infrastructure, "Hack For Travel" developed a system in which innovators could have three kinds of interactions with their mentors. First, a couple of mentors were assigned to each team. These mentors could frequently jump in the discussion going on between team members and giving advices regarding both tourism challenges and business potential. Second, there were three pit stops, organized at the start, in which teams had to present their advancements to mentors. As one of the innovators (i10) said in the interview:

Every 8-10 hours there was the external support from mentors through Slack. We told them about the advancements, and they said "yes, maybe push more on this issue, this one is perhaps premature". So even the support we have received from these mentors helped guide the creation of the idea.

\begin{tabular}{llll}
\hline $\begin{array}{l}\text { Research } \\
\text { question }\end{array}$ & $\begin{array}{l}\text { Processes } \\
\text { RQ2 }\end{array}$ & Label & Meaning \\
\hline Process 4 & $\begin{array}{l}\text { Technological } \\
\text { education } \\
\text { Idea (knowledge) co- } \\
\text { creation }\end{array}$ & $\begin{array}{l}\text { Organization of the web-platform and stakeholder } \\
\text { education } \\
\text { Systematization of the web-platform to favor the } \\
\text { interactions among the stakeholders involved in the } \\
\text { idea development, overcoming online barriers } \\
\text { Development of mixed hackathon that could exploit } \\
\text { benefits from the online and the offline formula }\end{array}$
\end{tabular}

Source(s): Authors' elaboration
Innovative ideas through hackathons

423


EJIM

25,6

Third, there were other mentors specifically expert of some fields that were available to anyone who needed them, as explained by i10:

When we had a lack of skills, we made a call and there was someone (mentor) who maybe could give us elements to help us refine the idea. For example, if I needed some information about blockchain, there was an expert about that! It was an ecosystem of knowledge sharing. An ecosystem of 36 hours that collaborates, creates a network, to make ideas more solid and valuable.

As a result, this process-idea co-creation (Table 4)-generates knowledge that is co-created by the different stakeholders that are involved in the process: the sponsors that raise the problems, the innovators that have the idea, the mentors that help developing such idea and the organizers that give all these actors the possibility to share knowledge through the development of an OI platform, i.e. the hackathon. i10 said:

It is an open innovation operation. As a sponsor, I go and look outside my perimeter for the innovations I need! Through a hackathon, I am sure to find brilliant, smart, fast and dynamic minds with whom I can chat and accelerate my innovative process.

Nevertheless, the online formula could represent a barrier in terms of interactions and knowledge sharing as the lack of offline human relations could make team members losing interest for the development of their projects (Hjalmarsson et al., 2017). As one of the mentors (i4) said:

There is a difference from the point of view of interaction because clearly when you are offline it is easier to immediately empathize with who you have to mentor, while on the online it is harder.

For this reason, organizing the event in the most precise way as possible and through the right technology was fundamental, not only to manage the hackathon, but also to favor an effective flow of knowledge and interactions among the different parties. According to the mentor (i5):

An excellent organization is needed even more in an online hackathon. If in presence there is a problem you can make up for it with sympathy, but online you have more difficulty in doing it. So, the more you organize before the less problems you create then during the event.

This concept has been also reinforced by the organizer i1:

Compared to the physical one, the thing I take home is the organizational part: while in a physical hackathon you can rely a little on improvisation, in a digital one everything must be absolutely perfect.

Indeed, although the concerns related to possible barriers faced by the organizers, the capillary organization of the event allowed to overcome such difficulties as it is possible to read from the words of one of the organizers on the "Hack For Travel" website:

The most extraordinary thing was to see 1,300 people between innovators and mentors working together and making experiences and skills available, creating a sense of community and, despite the mediation of the network and platforms, the flow of emotions and energies. All the organizers were overwhelmed by this wave and we spent 48 hours in a constant stream of connection, messages, live, and it was like everyone really was in the same room.

In addition, the online nature of the event gave the possibility to participate to people coming from every part of the country, overcoming geographical barriers that would have made more difficult for many people to reach the event, as underlined by i7:

In a physical hackathon of course, you manage to attract people from the area mainly. But when you do an online hackathon, distances are eliminated.

The organizational capabilities and the technological asset, along with the possibility to host such a diversified human capital, favor the knowledge exchange and co-creation, although 
the difficulties that an online hackathon platform presents as opposite to a physical one. However, these findings suggest that, in order to be effective as physical ones, online platforms need to be organized according to different criteria in order to achieve positive results, i.e. the creation of valuable ideas that represent the seed of innovation for companies and institutions. For this reason, a sixth process-hackathon hybridization (Table 4)-was identified as a possible development for hackathons that could merge the benefits coming from the physical ones with those coming from the online ones. As i2 suggests, indeed:

We had proof that online hackathons work, although some limitations typical of an online formula emerged. In the future, it will become a hybrid experience, so there will be who will choose to do it online and who will come to do it on site. I'm sure the future of hackathons will be that in some way.

\section{Discussion and conclusions}

This study allows to better understanding the role of hackathon platforms as a driver to boost innovative ideas in the tourism industry (Briscoe and Mulligan, 2014). First, findings highlighted how hackathon platforms emerge as useful citizen engagement tools (Cappa et al., 2020a, b; Sigala and Ukpabi, 2019) by showing the organization and the processes needed to engage several diverse actors in carrying out collaborative innovation generation. In addition, the analysis shows that hackathons can address social problems towards a sustainable value creation (Orefice and Nyarko, 2020; Vrontis et al., 2021) not just in ordinary periods but also in time of crises. Indeed, the possibility of developing a hackathon in an online form shows the speed with which it is possible to address unexpected shocks by involving the most relevant parties involved in a given context, towards the adoption of shared innovative solutions. That uncovers how hackathons may generate a social impact being committed to social responsibility and aiming to find answers to the challenges the world is facing. It clearly emerged from the analysis of the case. This is in line with studies that discuss on new products and services that address social needs or new processes that make use of social relations to deliver products and services in more efficient ways (Phills et al., 2008). Such findings, along with the stakeholder engagement, underline the sustainable nature of hackathon platforms as tools to address relevant social issues to which trying to provide innovative solutions (Trabucchi et al., 2020).

Our aim was to investigate the role and functions of hackathon platforms as OIIs and explore how they encourage the collaboration among participants as a source of idea generation. Through the identification of the processes that characterize the hackathon platform's functioning, our study offers several contributions to the existing literature, shedding new light on the peculiar role of hackathon platforms working as OIIs. The analysis of the case "Hack For Travel" allowed giving answer to the two research questions posed in the introduction. Six processes have been discovered, equally distributed for the two research questions.

The first three processes refer to the organization and development of the hackathon. They underline the technology's relevance as a key driver for an effective development of the event, in line with its digital nature. The selection of the right technology to use and its effective organization (Process 1-technological infrastructure setup) are at the base of the sustainable process of idea generation. In fact, it creates a platform on which stakeholders can easily find and offer knowledge and meanwhile co-create innovative projects in a non-traditional creative way of thinking (Toros et al., 2020). Second, in line with Troise et al. (2021), process 2 (stakeholder selection) and process 3 (awareness creation) revealed the capability of hackathon platform to engage a multitude of users and, in so doing, to generate network effects. Accordingly, it facilitates the collaborations among different stakeholders bringing together people with diverse backgrounds, experience and expertise (Pe-Than and Herbsleb, 2019).

Furthermore, findings highlighted how "Hack For Travel" has been able to facilitate the interaction and knowledge sharing and creation among the participants, in line with the OI 
EJIM

25,6

426

approach. It increased the combination of the complementary capabilities, thus, working as facilitator and knowledge-broker as already stated by the previous thoughts of Sieg et al. (2010) and Verona et al. (2006), as identified in the process 5 (Idea/knowledge co-creation). In addition, "Hack For Travel" demonstrated its educational value offered to its participants. Process 4 (Technological education) highlights the role of organizers in educating participants to develop technological capabilities to favor the interaction among them. Moreover, hackathon platforms manifest their educational role also in giving the opportunity to young innovators to challenge themselves in a high-intensive innovation environment collaborating with the most important experts and organizations of the industry.

Process 6 (hackathon hybridization) finally refers to the opportunity to merge online activities with offline ones. The case of "Hack For Travel" shows a new way of generating innovations relying on digital technologies. Doing massive use of ICT, hackathons can foster solutions more quickly than other actions because they are able to engage a bigger number of stakeholders and in a faster manner. Such findings show that the growing phenomenon of digital platforms is increasingly relevant for the innovation of the tourism industry (Gössling, 2020). In its digital form, a hackathon platform should develop and effectively organize the right technology to develop such a process of innovation generation, while carefully selecting the most relevant and useful stakeholders to achieve the goal of generating new solutions to economic and social issues (Vrontis et al., 2021). In addition, hackathons should be able to create the right stimuli to all the participants involved overcoming barriers typical of online peer relationships.

The research makes both theoretical and practical contributions. Theoretically, the study advances the understanding of the role of digital technologies for the development of co-designed business ideas (Cuomo et al., 2021; Urbinati et al., 2020) by highlighting how hackathon platforms organize digital events to foster OI and find innovative solutions to well-established socioeconomic problems characterizing the tourism industry, through the involvement of multiple stakeholders (Carlisle et al., 2013; Marques and Borba, 2017). Findings enrich literature on hackathon operations and structure by identifying which processes need to be implemented for making digital hackathons sources of OI for the industry (Briscoe and Mulligan, 2014) giving more insights about the transposition of the event from an offline modality towards an online one. In doing so, this paper advances the understanding of several stakes, such as the capacity of online hackathons to involve a greater number of participants, to reach a bigger geographical area and to cover a wide range of initiatives. In these sense, online hackathons are interesting fields to experiment how digitalization may create not just economic and environmental sustainability, but also social value in line with the principles of Sustainable Development Goals (SDGs). An additional and associated contribution of this study is the perspective shift from the value chain of the industrial logic to the value constellation supported by an OII.

From the managerial viewpoint, we proposed a list of practical processes that hackathon platforms' organizers should carefully consider in developing digital events to support heterogenous participants to engage in knowledge transfer and integration processes to face OI challenges. In addition, two main recommendations are proposed. "Hack For Travel" took place entirely online. However, our findings show that its experience suggests that online hackathon platforms are at least as effective as physical ones to generate innovative solutions in a bottom-up process although some physiological limitations they may face due to the different nature of the interactions going on among the participants (Baggio and Del Chiappa, 2014; Khalis and Mikami, 2018). Future developments could try to merge the two approaches to exploit benefits coming from all of them (Process 6). Furthermore, even if "Hack For Travel" made high use of ICT tools to create a "warm atmosphere" to build a diffuse sense of community, future experiences of online hackathons have to experiment additional tools that new technologies already make available with the goal to reduce the barriers among participants. For example, this is the case of virtual reality and augmented reality technologies that allow for building new immersive experiences and applications. 
This study is not without limitations that may however stimulate future lines of inquiry. Being of qualitative nature, the study did not target to generalize results but to develop topics that are of interest for researching hackathon platforms in hospitality and tourism. Future research could try to quantitatively analyze the effectiveness of the identified processes on effective innovation generation, for example, by looking at the number of patents granted by hackathon innovators. Moreover, future studies may try to address more precisely differences between online and offline hackathons to underline different implications of the two formula and the potential advantages brought by hybrid forms of digital platforms that also favor physical interactions or vice versa. Finally, the study was conducted in a context under high pressure due to the crisis triggered by COVID-19. Future researches can consider the analysis of other hackathons that will be run out of the pandemic. This can help to draw a deeper portrait of this challenging phenomenon.

\section{References}

Acciarini, C., Borelli, F., Capo, F., Cappa, F. and Sarrocco, C. (2021), "Can digitalization favour the emergence of innovative and sustainable business models? A qualitative exploration in the automotive sector", Journal of Strategy and Management, Vol. ahead-of-print No. ahead-of-print, in press, doi: 10.1108/jsma-02-2021-0033.

Adamczyk, S., Bullinger, A.C. and Möslein, K.M. (2012), "Innovation contests: a review, classification and outlook", Creativity and Innovation Management, Vol. 21 No. 4, pp. 335-360.

Aleksić, D., Rangus, K. and Slavec Gomezel, A. (2021), "Microfoundations of SME open innovation: the role of help, knowledge sharing and hiding", European Journal of Innovation Management, Vol. ahead-of-print No. ahead-of-print, in press, doi: 10.1108/ejim-10-2020-0411.

Antikainen, M., Mäkipää, M. and Ahonen, M. (2010), "Motivating and supporting collaboration in open innovation”, European Journal of Innovation Management, Vol. 13 No. 1, pp. 100-119.

Baggio, R. and Del Chiappa, G. (2014), "Real and virtual relationships in tourism digital ecosystems", Information Technology and Tourism, Vol. 14 No. 1, pp. 3-19.

Baglieri, D. and Consoli, R. (2009), "Collaborative innovation in tourism: managing virtual communities", TQM Journal, Vol. 21 No. 4, pp. 353-364.

Baregheh, A., Rowley, J. and Sambrook, S. (2009), "Towards a multidisciplinary definition of innovation”, Management Decision, Vol. 47 No. 8, pp. 1323-1339.

Benbasat, I., Goldstein, D.K. and Mead, M. (1987), "The case research strategy in studies of information systems", MIS Quarterly, Vol. 11 No. 3, pp. 369-386.

Blind, K., Petersen, S.S. and Riillo, C.A.F. (2017), "The impact of standards and regulation on innovation in uncertain markets", Research Policy, Elsevier B.V., Vol. 46 No. 1, pp. 249-264.

Bogers, M., Zobel, A.K., Afuah, A., Almirall, E., Brunswicker, S., Dahlander, L., Frederiksen, L., Gawer, A., Gruber, M., Haefliger, S., Hagedoorn, J., Hilgers, D., Laursen, K., Magnusson, M.G., Majchrzak, A., McCarthy, I.P., Moeslein, K.M., Nambisan, S., Piller, F.T., Radziwon, A., Rossi-Lamastra, C., Sims, J. and Ter Wal, A.L.J. (2017), "The open innovation research landscape: established perspectives and emerging themes across different levels of analysis", Industry and Innovation, Routledge, Vol. 24 No. 1, pp. 8-40, doi: 10.1080/13662716.2016.1240068.

Bolici, F., Acciarini, C., Marchegiani, L. and Pirolo, L. (2020), "Innovation diffusion in tourism: how information about blockchain is exchanged and characterized on twitter", TQM Journal, Vol. ahead-of-print No. ahead-of-print, in press, doi: 10.1108/TQM-01-2020-0016.

Boudreau, K.J. and Lakhani, K.R. (2009), "How to manage outside innovation", MIT Sloan Management Review, Vol. 50 No. 4, pp. 69-76.

Bresciani, S., Ferraris, A. and Del Giudice, M. (2018), "The management of organizational ambidexterity through alliances in a new context of analysis: Internet of Things (IoT) smart city projects", Technological Forecasting and Social Change, Elsevier, Vol. 136, pp. 331-338.

\section{Innovative ideas through hackathons}


EJIM

25,6

Briscoe, G. and Mulligan, C. (2014), Digital Innovation: The Hackathon Phenomenon, Creativeworks, London, Vol. 6, pp. 1-13.

Brunswicker, S. and Vanhaverbeke, W. (2015), "Open innovation in small and medium-sized enterprises (SMEs): external knowledge sourcing strategies and internal organizational facilitators", Journal of Small Business Management, Vol. 53 No. 4, pp. 1241-1263.

Buhalis, D. (2019), "Technology in tourism-from information communication technologies to eTourism and smart tourism towards ambient intelligence tourism: a perspective article”, Tourism Review, Vol. 75 No. 1, pp. 267-272.

Cappa, F., Rosso, F., Hayes, D., Cappa, F., Rosso, F. and Hayes, D. (2019), "Monetary and social rewards for crowdsourcing”, Sustainability 2019, Multidisciplinary Digital Publishing Institute, Vol. 11 No. 10, p. 2834.

Cappa, F., Rosso, F. and Capaldo, A. (2020a), "Visitor-sensing: involving the crowd in cultural heritage organizations”, Sustainability (Switzerland), Vol. 12 No. 4, doi: 10.3390/su12041445.

Cappa, F., Rosso, F., Giustiniano, L. and Profiri, M. (2020b), "Nudging and citizen science: the effectiveness of feedback in energy-demand management", Journal of Environmental Management, Vol. 269, p. 110759.

Cappa, F., Oriani, R., Peruffo, E. and McCarthy, I. (2021), "Big data for creating and capturing value in the digitalized environment: unpacking the effects of volume, variety, and veracity on firm performance", Journal of Product Innovation Management, Vol. 38 No. 1, pp. 49-67.

Carlisle, S., Kunc, M., Jones, E. and Tiffin, S. (2013), "Supporting innovation for tourism development through multi-stakeholder approaches: experiences from Africa", Tourism Management, Vol. 35, pp. 59-69.

Chesbrough, H. (2003), "The logic of open innovation: managing intellectual property", California Management Review, Vol. 45 No. 3, pp. 33-58.

Chowdhury, J. (2012), "Hacking health: bottom-up innovation for healthcare", Technology Innovation Management Review, Vol. 2 No. 7, pp. 31-35.

Colombo, M.G., Piva, E. and Rossi-Lamastra, C. (2014), "Open innovation and within-industry diversification in small and medium enterprises: the case of open source software firms", Research Policy, Elsevier B.V., Vol. 43 No. 5, pp. 891-902.

Cuomo, M.T., Tortora, D., Foroudi, P., Giordano, A., Festa, G. and Metallo, G. (2021), "Digital transformation and tourist experience co-design: big social data for planning cultural tourism", Technological Forecasting and Social Change, Elsevier, Vol. 162, June 2020, p. 120345.

Dahlander, L. and Gann, D.M. (2010), "How open is innovation?", Research Policy, Vol. 39 No. 6, pp. 699-709.

Day, G.S. and Schoemaker, P.J.H. (2016), "Adapting to fast-changing markets and technologies", California Management Review, Vol. 58 No. 4, pp. 59-77.

Del Vecchio, P., Mele, G., Ndou, V. and Secundo, G. (2018), "Open innovation and social big data for sustainability: evidence from the tourism industry", Sustainability (Switzerland), Vol. 10 No. 9, doi: 10.3390/su10093215.

Denicolai, S., Zucchella, A. and Magnani, G. (2021), "Internationalization, digitalization, and sustainability: are SMEs ready? A survey on synergies and substituting effects among growth paths", Technological Forecasting and Social Change, Elsevier, Vol. 166, December 2020, p. 120650.

D'Angelo, V. and Magnusson, M. (2020), "A bibliometric map of intellectual communities in frugal innovation literature", IEEE Transactions on Engineering Management, Vol. 68 No. 3, pp. 653-666.

Egger, R., Gula, I. and Walcher, D. (2016), in Open Tourism. Open Innovation, Crowdsourcing and CoCreation Challenging the Tourism Industry, Springer.

Eisenhardt, K.M. (1989), "Building theories from case study research", Academy of Management Review, Vol. 14 No. 4, pp. 532-550, doi: 10.5465/amr.1989.4308385. 
Eisenhardt, K.M. and Graebner, M.E. (2007), "Theory building from cases: opportunities and challenges", Academy of Management Journal, Vol. 50 No. 1, pp. 25-32, doi: 10.5465/AMJ.2007.24160888.

Evans, D.S. and Schmalensee, R. (2016), Matchmakers: the New Economics of Multisided Platforms, Harvard Business Review Press, Boston.

Ferraris, A., Santoro, G. and Bresciani, S. (2017), 'Open innovation in multinational companies' subsidiaries: the role of internal and external knowledge", European Journal of International Management, Vol. 11 No. 4, pp. 452-468.

George, G., Haas, M.R. and Pentland, A. (2014), "Big data and management", The Academy of Management Journal, Vol. 57 No. 2, pp. 321-326.

Ghezzi, A., Gabelloni, D., Martini, A. and Natalicchio, A. (2017), "Crowdsourcing: a review and suggestions for future research", International Journal of Management Reviews, Vol. 20 No. 2, pp. 343-363.

Gössling, S. (2020), "Technology, ICT and tourism: from big data to the big picture", Journal of Sustainable Tourism, Routledge, Vol. 29 No. 5, pp. 849-858.

Gomezelj, D.G. (2016), "A systematic review of research on innovation in hospitality and tourism", International Journal of Contemporary Hospitality Management, Vol. 28 No. 3, pp. 516-558.

Granados, C. and Pareja-Eastaway, M. (2019), "How do collaborative practices contribute to innovation in large organisations? The case of hackathons", Innovation: Organization and Management, Routledge, Vol. 21 No. 4, pp. 487-505.

Grissemann, U., Plank, A. and Brunner-Sperdin, A. (2013), "Enhancing business performance of hotels: the role of innovation and customer orientation", International Journal of Hospitality Management, Elsevier, Vol. 33 No. 1, pp. 347-356.

Gummesson, E. (2017), Case Theory in Business and Management: Reinventing Case Study Research, SAGE Publications, London.

Haugland, S.A., Ness, H., Grønseth, B.O. and Aarstad, J. (2011), "Development of tourism destinations an integrated multilevel perspective", Annals of Tourism Research, Vol. 38 No. 1, pp. 268-290.

Hjalmarsson, A., Juell-Skielse, G. and Johannesson, P. (2017), "Open digital innovation contest”, in Open Digital Innovation, Springer, Cham, pp. 11-21.

Howells, J. (2006), "Intermediation and the role of intermediaries in innovation", Research Policy, Vol. 35 No. 5, pp. 715-728.

Huang, X.X., Hu, Z.P., Liu, C.S., Yu, D.J. and Yu, L.F. (2016), "The relationships between regulatory and customer pressure, green organizational responses, and green innovation performance", Journal of Cleaner Production, Elsevier, Vol. 112, pp. 3423-3433.

Hutter, K., Hautz, J., Füller, J., Mueller, J. and Matzler, K. (2011), "Communitition: the tension between competition and collaboration in community-based design contests", Creativity and Innovation Management, Vol. 20 No. 1, pp. 3-21.

Karlsen, J. and Løvlie, A.S. (2017), "You can dance your prototype if you like': independent filmmakers adapting the hackathon", Digital Creativity, Taylor \& Francis, Vol. 28 No. 3, pp. 224-239.

Kennedy, S., Whiteman, G. and van den Ende, J. (2017), "Radical innovation for sustainability: the power of strategy and open innovation", Long Range Planning, Elsevier, Vol. 50 No. 6, pp. $712-725$.

Khalis, A. and Mikami, A.Y. (2018), "Talking face-to-Facebook: associations between online social interactions and offline relationships", Computers in Human Behavior, Vol. 89, January, pp. 88-97.

Kitsios, F. and Kamariotou, M. (2018), "Open data hackathons: an innovative strategy to enhance entrepreneurial intention”, International Journal of Innovation Science, Vol. 10 No. 4, pp. 519-538.

Kokshagina, O., Le Masson, P. and Bories, F. (2017), "Fast-connecting search practices: on the role of open innovation intermediary to accelerate the absorptive capacity", Technological Forecasting and Social Change, Elsevier, Vol. 120, pp. 232-239. 
EJIM

25,6

Komssi, M., Kauppinen, M., Töhönen, H., Lehtola, L. and Davis, A.M. (2015), "Roadmapping problems in practice: value creation from the perspective of the customers", Requirements Engineering, Vol. 20 No. 1, pp. 45-69.

Kuang, L., Huang, N., Hong, Y. and Yan, Z. (2019), "Spillover effects of financial incentives on nonincentivized user engagement: evidence from an online knowledge exchange platform", Journal of Management Information Systems, Routledge, Vol. 36 No. 1, pp. 289-320.

Lalicic, L. (2018), "Open innovation platforms in tourism: how do stakeholders engage and reach consensus?", International Journal of Contemporary Hospitality Management, Vol. 30 No. 6, pp. 2517-2536.

Lee, S., Park, G., Yoon, B. and Park, J. (2010), "Open innovation in SMEs-An intermediated network model”, Research Policy, Elsevier B.V., Vol. 39 No. 2, pp. 290-300.

Lifshitz-Assaf, H., Lebovitz, S. and Zalmanson, L. (2020), "Minimal and adaptive coordination: how hackathons' projects accelerate innovation without killing it", Academy of Management Journal, Vol. 64 No. 3, doi: 10.5465/amj.2017.0712.

Love, J.H., Roper, S. and Vahter, P. (2014), "Learning from openness: the dynamics of breadth in external innovation linkages”, Strategic Management Journal, Vol. 35 No. 11, pp. 1703-1716.

Marasco, A., De Martino, M., Magnotti, F. and Morvillo, A. (2018), "Collaborative innovation in tourism and hospitality: a systematic review of the literature", International Journal of Contemporary Hospitality Management, Vol. 30 No. 6, pp. 2364-2395.

Marques, L. and Borba, C. (2017), "Co-creating the city: digital technology and creative tourism", Tourism Management Perspectives, Elsevier, Vol. 24, pp. 86-93.

McIntyre, D. and Srinivasan, A. (2017), "Networks, platforms, and strategy: emerging views and next steps", Strategic Management Journal, Vol. 38, pp. 141-160.

Medina Angarita, M.A. and Nolte, A. (2020), "What do we know about hackathon outcomes and how to support them? - a systematic literature review", in Lecture Notes in Computer Science (Including Subseries Lecture Notes in Artificial Intelligence and Lecture Notes in Bioinformatics), Vol. 12324, LNCS, pp. 50-64.

Miles, M.B. and Huberman, A.M. (1984), "Drawing valid meaning from qualitative data: toward a shared craft", Educational Researcher, Vol. 13 No. 5, pp. 20-30.

Morgan, J. and Wang, R. (2010), "Tournaments for ideas", California Management Review, Vol. 52 No. 2, pp. 77-97.

Mount, M. and Martinez, M.G. (2014), "Social media: a tool for open innovation", California Management Review, Vol. 56 No. 4, pp. 124-143.

Natalicchio, A., Messeni Petruzzelli, A., Cardinali, S. and Savino, T. (2018), "Open innovation and the human resource dimension: an investigation into the Italian manufacturing sector", Management Decision, Vol. 56 No. 6, pp. 1271-1284.

Orefice, C. and Nyarko, N. (2020), "Sustainable value creation in event ecosystems-a business models perspective”, Journal of Sustainable Tourism, Routledge, Vol. 0 No. 0, pp. 1-16.

Pe-Than, E.P.P. and Herbsleb, J.D. (2019), "Understanding hackathons for science: collaboration, affordances, and outcomes", in Lecture Notes in Computer Science (Including Subseries Lecture Notes in Artificial Intelligence and Lecture Notes in Bioinformatics), Vol. 11420, LNCS, pp. 27-37.

Phills, J.A., Deiglmeier, K. and Miller, D.T. (2008), "Rediscovering social innovation”, Stanford Social Innovation Review, Vol. 6 No. 4, pp. 34-43.

Presenza, A., Micera, R., Splendiani, S. and Chiappa, G. Del. (2014), "Stakeholder e-involvement and participatory tourism planning: analysis of an Italian case study", International Journal of Knowledge-Based Development, Vol. 5 No. 3, pp. 311-328.

Rezaei, S., Ali, F., Amin, M. and Jayashree, S. (2016), "Online impulse buying of tourism products: the role of web site personality, utilitarian and hedonic web browsing", Journal of Hospitality and Tourism Technology, Vol. 7 No. 1, pp. 60-83. 
Roper, S. and Tapinos, E. (2016), "Taking risks in the face of uncertainty: an exploratory analysis of green innovation", Technological Forecasting and Social Change, The Authors, Vol. 112, pp. 357-363.

Sieg, J.H., Wallin, M.W. and Von Krogh, G. (2010), "Managerial challenges in open innovation: a study of innovation intermediation in the chemical industry", $R$ and D Management, Vol. 40 No. 3, pp. 281-291.

Sigala, M. (2020), "Tourism and COVID-19: impacts and implications for advancing and resetting industry and research", Journal of Business Research, Elsevier, Vol. 117, June, pp. 312-321.

Sigala, M. and Ukpabi, D. (2019), in Pesonen, J. and Neidhardt, J. (Eds), "Citizen engagement and entrepreneurship : implications for sustainable tourism development", Information and Communication Technologies in Tourism 2019: Proceedings of the International Conference in Nicosia, Cyprus, Springer, January 30-February 1, 2019, pp. 396-407.

Siggelkow, N. (2007), "Persuasion with case studies", Academy of Management Journal, Vol. 50 No. 1, pp. 20-24.

Spender, J.C., Corvello, V., Grimaldi, M. and Rippa, P. (2017), "Startups and open innovation: a review of the literature", European Journal of Innovation Management, Vol. 20 No. 1, pp. 4-30.

Stickdorn, M., Schneider, J., Andrews, K. and Lawrence, A. (2011), This is Service Design Thinking: Basics, Tools, Cases, Wiley, Hoboken, NJ, Vol. 1.

Strauss, A. and Corbin, J. (1997), Grounded Theory in Practice, SAGE Publications, Thousand Oaks.

Terwiesch, C. and $\mathrm{Xu}, \mathrm{Y}$. (2008), "Innovation contests, open innovation, and multiagent problem solving", Management Science, Vol. 54 No. 9, pp. 1529-1543.

Toros, K., Kangro, K., Lepik, K.L., Bugarszki, Z., Sindi, I., Saia, K. and Medar, M. (2020), “Co-creation of social services on the example of social hackathon: the case of Estonia", International Social Work. doi: 10.1177/0020872820904130.

Trabucchi, D., Bellis, P., Di Marco, D., Buganza, T. and Verganti, R. (2020), "Attitude vs involvement: a systematic literature review at the intersection between engagement and innovation", European Journal of Innovation Management. doi: 10.1108/EJIM-05-2020-0171.

Troise, C., Matricano, D. and Sorrentino, M. (2021), "Open Innovation Platforms: exploring the importance of knowledge in supporting online initiatives", Knowledge Management Research and Practice, Vol. 19 No. 2, pp. 208-216.

Urbinati, A., Landoni, P., Cococcioni, F. and De Giudici, L. (2020), "Stakeholder management in open innovation projects: a multiple case study analysis", European Journal of Innovation Management. doi: 10.1108/EJIM-03-2020-0076.

Verona, G., Prandelli, E. and Sawhney, M. (2006), "Innovation and virtual environments: towards virtual knowledge brokers”, Organization Studies, Vol. 27 No. 6, pp. 765-788.

Vrontis, D., Morea, D., Basile, G., Bonacci, I. and Mazzitelli, A. (2021), "Consequences of technology and social innovation on traditional business model", Technological Forecasting and Social Change, Elsevier, Vol. 170, December 2020, 120877.

Yin, R.K. (1994), Case Study Research. Design and Methods, Sage, Thousand Oaks, CA.

\section{Corresponding author}

Stefano Franco can be contacted at: sfranco@luiss.it

For instructions on how to order reprints of this article, please visit our website:

www.emeraldgrouppublishing.com/licensing/reprints.htm

Or contact us for further details: permissions@emeraldinsight.com 